\title{
SOLAR BIOFUELS PRODUCTION WITH MICROALGAE
}

\author{
P.C. Hallenbeck *, M. Grogger, M. Mraz, and D. Veverka \\ Life Sciences Research Center, Department of Biology \\ United States Air Force Academy \\ 2355 Faculty Drive, USAF Academy, Colorado 80840 \\ *Author for correspondence, E-mail: patrick.hallenbeck.ctr@usafa.edu \\ 01-516-680-9038
}

With impending climate change and ever decreasing supplies of easily extractable fossil fuel, means to produce renewable and sustainable replacement fuels are being sought. Plants or algae appear ideal since they can use sunlight to fix $\mathrm{CO}_{2}$ into usable fuel or fuel feedstocks. However, as the world population approaches the $10^{10}(10$ billion) mark, the use of agricultural land to produce fuel instead of food cannot be justified. Microalgal biofuel production is under intense investigation due to its promise as a sustainable, renewable biofuel that can be produced using non-arable land and brackish or non-potable water. Some species accumulate high levels of TAGs (triacylglycerols) that can be converted to fatty acid esters suitable as replacement diesel fuels. However, there are many technical barriers to the practical application of microalgae for biofuel production and thus a number of significant challenges need to be met before microalgal biodiesel production becomes a practical reality. These include developing cost-effective cultivation strategies, low energy requiring harvesting technologies, and energy efficient and sustainable lipid conversion technologies. The large culture volumes that will be necessary dictate that the necessary nutrients come from wastewaters, such as the effluents from secondary treatment of sewage. Economical and energy sparing harvesting will require the development of novel flocculation or floatation strategies and new methods of oil extraction/catalysis that avoid the extensive use of solvents. Recent advances in these critical areas are reviewed and some of the possible strategies for moving forward are outlined.

Keywords: biofuels; microalgae; pyrolysis; biodiesel; hydrogen; methane digestion 


\section{Introduction}

Microalgae are increasingly being proffered as a tenable solution to finite fossil fuel supplies. Although an upswing in new technologies has increased the potential for capturing previously unavailable oil reserves, the impact of continued greenhouse gas emissions remains. Ever increasing commercialization efforts for alternative fuel production continues to gather momentum. Greatly expanded biofuels production is being touted as an at least partial solution to the twin problems of climate change driven by excessive fossil fuel combustion and the dwindling supply of evermore difficultly extracted fossil fuels. Of course, no matter the actual biofuel, or the specific process used to make it, the ultimate energy source behind biofuels is solar irradiation driven photosynthesis.

Although several biofuels, notably bioethanol and biodiesel, are currently being produced in significant industrial quantities, $6.9 \times 10^{8}$ barrels in 2011 [1], there is an urgent need to develop other biofuels for a number of reasons. First generation biofuels are seen as competing with food production for resources; land, water and nutrients [2-11]. Moreover, these fuels, in particular ethanol from corn, have only a very small net energy gain (positive EROI, see Table 1 for nomenclature used in this review).

\section{Table 1. Nomenclature}

$A D$

Anaerobic Digestion, the conversion of organic matter to methane

CAPEX Capital expenditures

EROI Energy Return on Investment. The net amount of energy generated taking into account the various energy inputs. Also termed NER.

LCA Life Cycle Analysis. The analysis of a production process that takes into account the various impacts from "well to wheel"

OPEX Operational Expenditures

PAR Photosynthetically Active Radiation (Light in the visible range that is effectively converted by photosynthesis, 400-700nm) 
PE Photosynthetic Efficiency, the efficiency of conversion of light energy to chemical energy

Finally, given the constraints on land-based plant productivities, enormous surface areas would be required to make significant impacts in terms of reductions in fossil fuel use. For example, to replace the amount of oil used in the US transportation sector in 2014, 4474 million BOE [12] with biofuels would require $19.3 \times 10^{6} \mathrm{~km}^{2}$ if soy beans were used (40 gallons/acre) or $1.93 \times 10^{6}$ $\mathrm{km}^{2}$ for corn (400 gallons/acre), clearly impossible since the arable land available in the US is $1.5 \times 10^{6} \mathrm{~km}^{2}$ [13]. On the other hand, biofuels produced from microalgae hold the promise of a much small footprint. Although actual large scale production figures are not available, a rough approximation can be made using reasonable extrapolations from existing data. Thus if a microalgal production system could produce $20 \mathrm{~g} \mathrm{~m}^{-2} \mathrm{~d}^{-1}$, and $30 \%$ of this could be converted to liquid fuel, the land area required for total transportation fuel replacement would be $4.47 \times 10^{5}$ $\mathrm{km}^{2}$. As well, the International Institute for Sustainable Development has concluded that the benefits to climate and $\mathrm{CO}_{2}$ reduction from replacing petroleum fuels with biofuels like ethanol are essentially zero [6]. Thus, more advanced biofuels are needed that can meet these challenges.

Microalgae, small, unicellular organisms that carry out plant type photosynthesis, possess several characteristics that make them attractive as potential biofuels producers [7-10]. Their autotrophic capabilities lend an element of flexibility in comparison to conventional fuels. As discussed in more detail below, algae can serve as feedstocks in a variety of processes that can produce fuels or fuel precursors (Figure 1). 


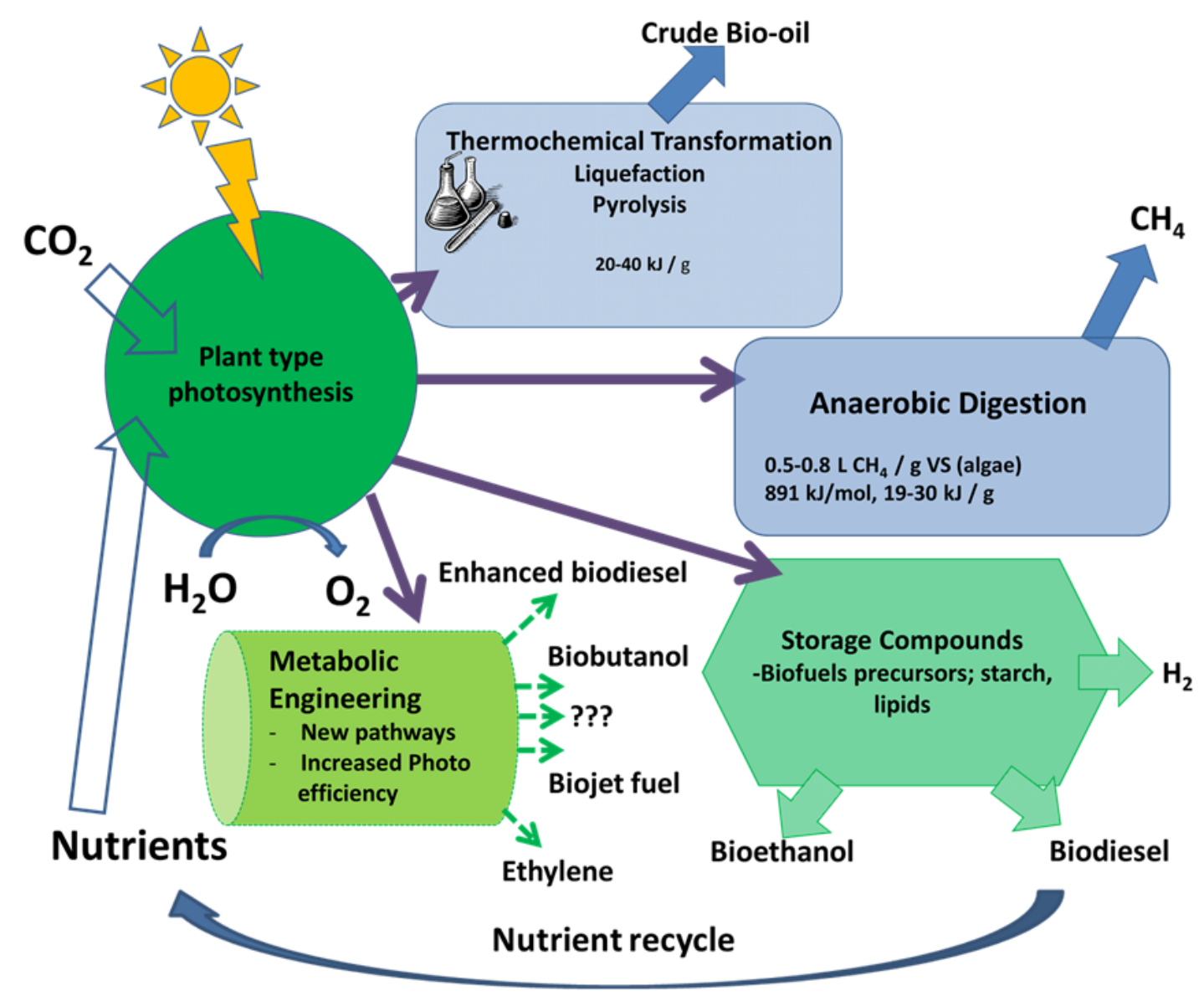

\section{Figure 1. Overview of Solar Biofuels Production by Microalgae}

Microalgae supported by basic nutrients, use captured solar energy and plant-type photosynthesis to split water and fix carbon dioxide. A variety of fuels can be made from the newly fixed carbon. The harvested algal biomass can be converted to bio-oil through hydrothermal liquefaction or pyrolysis or to methane through anaerobic digestion. Alternately, different algal storage materials can be converted to various fuels including ethanol, biodiesel, and hydrogen. Metabolic engineering could be used to enhance yields or to produce novel fuel compounds.

Microalgae are considered to have great potential due to; (1) their ability to be grown on marginal lands, (2), their use of wastewater as a medium for growth, often thereby effecting wastewater treatment as well, (3) their very fast growth rates as compared to land plants, often 
doubling their biomass in a single day or less, and (4) their ability to sequester flue gas emissions under appropriate conditions [14]. Depending on the production methods used, microalgae can provide a suite of commercially useful co-products [15-17]. In addition to triglyceride production for biofuels, the co-production of other even more valuable compounds, such as essential fatty acids and animal feeds, could bolster the economics of the whole process at the beginning when fuel production is modest. However, scale up and production costs must be considered to truly ascertain commodity values under present market conditions [18]. In some instances, when biofuel production is ramped up to scale, these valuable co-products could lose market value.

Microalgae carry out plant type photosynthesis, converting captured solar energy into chemical energy through the fixation of $\mathrm{CO}_{2}$. Although only specific products are naturally made, environmental, biochemical and molecular manipulations potentially greatly expand the scope, leading to practically limitless possibilities. A variety of biofuels are possible through different processes. Total algal biomass can be converted through direct thermochemical transformation to bio-oil, or through anaerobic digestion, to methane. Pyrolysis treatment under varying temperature regimens appears to have some potential for oil production. According to some, oil yields may range from $20-50 \%$ of the total ash free dry weight in some algae [19]. Alternatively, algae can be induced to produce high levels of storage compounds, starch or lipids, which can, when appropriately extracted and converted, be turned into the biofuels, bioethanol or biodiesel. A variety of novel methods for extraction and conversion remain to be explored including the use of enzymes to aid in extraction by weakening the cell wall [20]. Finally, future metabolic engineering [21-24] could produce improved strains with the ability to 
produce higher levels of natural biofuels, or endowed with the capacity to produce novel fuels, or fuel precursors, such as ethylene, biobutanol, hydrogen, or biojet fuel.

However, there are a number of serious challenges to implementation of microalgal-based biofuels production on a practical level [25]. These range from uncertainties on how to effectively and efficiently culture algae on a large scale, how to maintain the desired culture in the face of alien species, how to carry out low-cost, energy efficient harvesting, and the best methods for conversion to biofuels. In what follows, different aspects of algal culture and harvesting are briefly discussed and the various options for making fuels from algal biomass are presented in some detail.

\section{Algal biofuels; processes and products}

\subsection{Limits to photosynthesis}

Of course any process that relies on natural plant-type photosynthesis for solar energy conversion to various compounds or fuels will inevitably be limited by the inherent inefficiencies 
of photosynthesis (Figure 2).

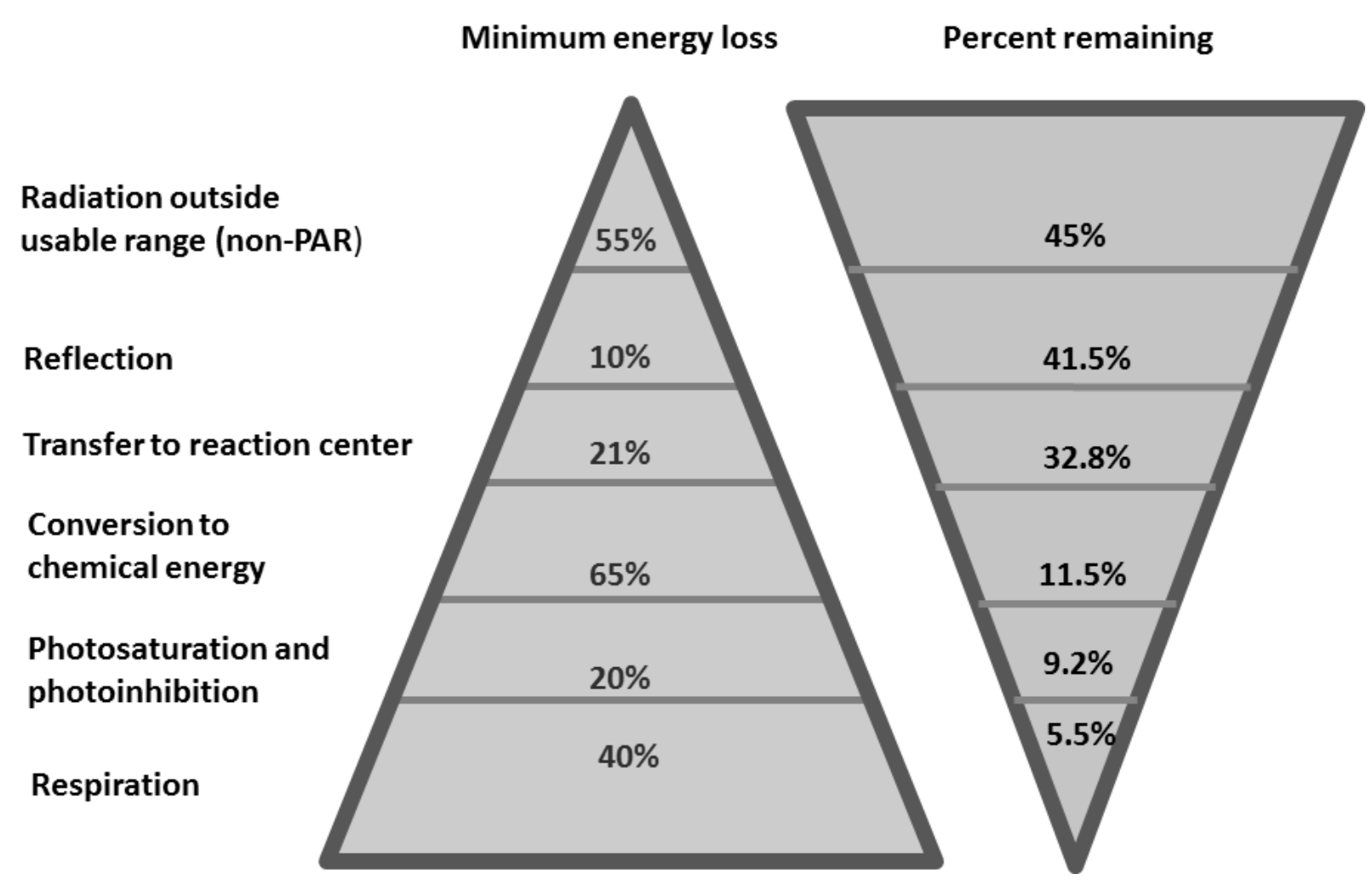

Figure 2. Solar Energy Train-the Limits of Photosynthesis

The various physical-chemical and biological processes that lead to energy loss are shown on the left, and on the right the effect on the limits of photosynthesis are given in terms of percent energy left.

The limiting factors are well known and have recently been discussed in detail $[9,10,26,27]$. Less than half of the incoming radiation (45\%) is actually able to be captured by the photosynthetic apparatus, some (about $10 \%$ ) gets reflected from the various biological structures, and there are loses $(21 \%)$ during transfer from the antenna complexes to the reaction centers. A large fraction (65\%) of the remaining $32.8 \%$ of incoming energy gets lost during transfer to chemical energy, much of this is in fact necessary in order to provide thermodynamic 
driving forces at the various steps. Finally, not all the energy can be used, especially at high light intensities and some of the newly made chemical energy is lost, burned during dark periods to maintain cell function (20\%), or to consume potentially damaging excess oxygen and to maintain cells during darkness (40\%). This lives only about $5.5 \%$ of incoming solar flux as the maximum of energy that can be finally converted into cell biomass or product.

These factors affect any process that relies on plant-type photosynthesis and in many ways fixes the absolute amount of energy that can be obtained in this way since very little can be done to affect the various losses. Small gains might be possible though some kind of bioengineering, to extend the range of light harvesting for example, or possibly to decrease losses during transfer to the reaction centers or during conversion to chemical energy. How much might be gained in this way is debatable since in fact natural evolution has had a few billion years to perfect this process.

\subsection{Algal cultivation and harvesting}

These aspects of algal biofuels have been recently reviewed in detail [7-10] and thus are only briefly presented here. These processes have been extensively examined, but, as yet, there is no consensus view as to the best way forward. Some of the issues are shown in Table 2.

Table 2. Issues in algal culture and harvesting

\begin{tabular}{lll}
\hline Concern & One option & Another option \\
\hline Organism & Specific uniculture & $\begin{array}{l}\text { Local species, } \\
\text { Mixed culture }\end{array}$ \\
Facility & Enclosed photobioreactor & Open, raceway pond \\
Growth Medium & Defined, N and P inputs & Wastewater \\
Harvesting & Centrifuging (High & $\begin{array}{l}\text { Flocculation, settling, } \\
\text { dissolved air flotation }\end{array}$
\end{tabular}


Of course, here how they will be cultivated will also determine what is possible in terms of algal culture. As indicated in Table 2, some propose the use of well characterized strains since these have been shown to possess some desirable characteristics, i.e. high lipid yields. However, these may not be competitive in open ponding operations which are probably more suitable for locally selected strains or even mixed cultures, which might even have certain beneficial characteristics [28]. Enclosed photobioreactors might permit the use of well characterized select strains since contamination can be kept to a minimum and this type of cultivation system is much more amenable to process control. Open ponds and photobioreactors each have their advantages and disadvantages, as shown in some detail in Table 3, and, in fact, the suitability of a particular process depends upon the desired application. Photobioreactors, in addition to offering the ability to more closely control the microalgal growth environment, appear to be inherently more productive on a volumetric basis (Table 3).

Table 3: Pros and cons of photobioreactors and open ponds

\begin{tabular}{|c|c|c|c|}
\hline Issue & Open ponds & Photobioreactor & Reference \\
\hline $\begin{array}{l}\text { Control of } \\
\mathrm{pH} \text {, temp, dissolved }\end{array}$ & Difficult & Easy & [29-31] \\
\hline $\begin{array}{l}\text { Ease of } \\
\text { contamination }\end{array}$ & High & Low & [29-31] \\
\hline Water evaporation & $\begin{array}{l}\text { High } \\
\geq 10 \mathrm{~L} \mathrm{~m}^{-2} \mathrm{~d}^{-1}\end{array}$ & $\begin{array}{l}\text { Low } \\
\geq 2 \mathrm{~L} \mathrm{~m}^{-2} \mathrm{~d}^{-1} \\
\text { (cooling) }\end{array}$ & [32] \\
\hline $\begin{array}{l}\text { Areal Productivity } \\
\left(\mathrm{m}^{-2}\right)\end{array}$ & Medium & Medium & [32-34] \\
\hline Volumetric & Medium & High & \\
\hline Productivity & $\begin{array}{l}0.07-0.18 \mathrm{~g} \mathrm{DW} \mathrm{L}^{-1} \\
\mathrm{~d}^{-1}\end{array}$ & $\begin{array}{l}0.4-1.9 \mathrm{~g} \mathrm{DW} \mathrm{L}^{-1} \\
\mathrm{~d}^{-1}\end{array}$ & \\
\hline OPEX & Low & High & {$[30,31,35]$} \\
\hline CAPEX & Low & High & \\
\hline \multirow[t]{2}{*}{ EROI } & Medium & Low & {$[32,36,37]$} \\
\hline & 8.3 & $0.2-4.5$ & \\
\hline
\end{tabular}


However, what counts here most is areal productivity, which determines the land area required, and on that basis open ponds and photobioreactors seem to have about equal performance [3234]. Most would agree that photobioreactors cannot be used for biofuel production since the CAPEX (capital expenses) and OPEX (operating expenses) associated with them are much higher than for open ponds $(\sim 3-5 \mathrm{X})$, making them uneconomical for such a low value product. This is a consequence of the relatively diffuse energy content of incident solar radiation. A simple calculation based solely on incident light intensities and assumed photosynthetic conversion efficiencies and fuel prices shows in fact that the economic constraints are formidable (Box 1).

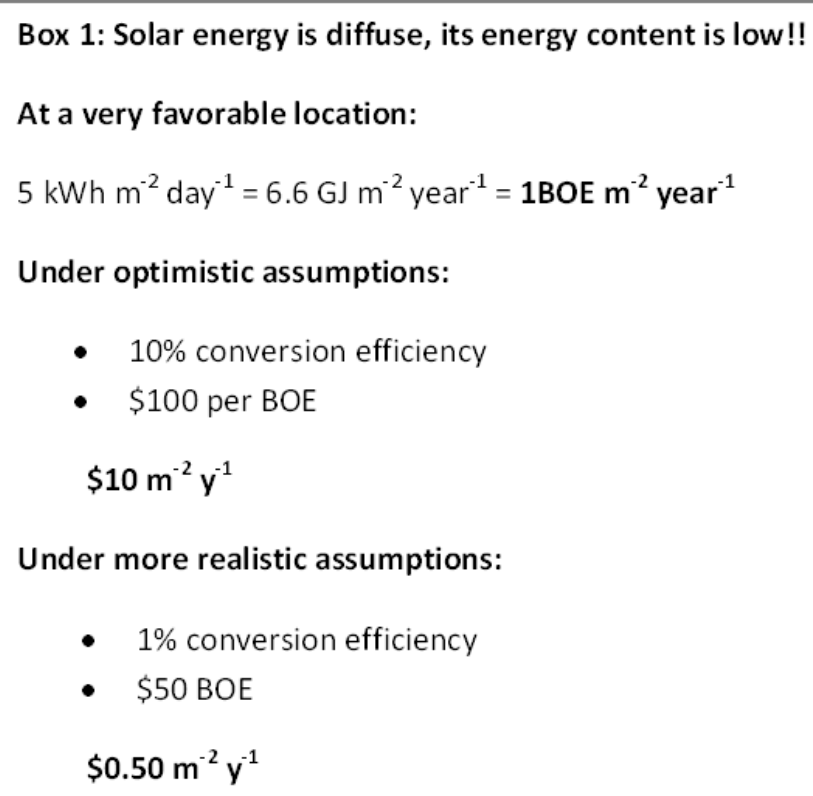

reactors, producing 100, $000 \mathrm{kgs}$ of algal biomass per year and found that the EROI was 8.3, 4.5, and 0.2 respectively [38]. Likewise, a metastudy of seven recent LCA studies concluded that in almost all cases open ponds showed a positive EROI whereas the photobioreactors had a largely negative EROI [36]. 
As well, although almost all laboratory studies reporting high growth rates and/or high lipid yields have been carried out using defined synthetic media, this would be impractical for large scale algal production for a number of reasons. One obvious negative is that nutrient addition in this manner could be quite costly at large scale. Even more significant is the large pressure that this would put on nitrogen and phosphate based fertilizers, essential for high-yielding food production. This would thus conceivably bring algae-based biofuels production in competition with food production. Fortunately, microalgae in general are known to thrive on a variety of wastewaters, in particular secondary effluents from sewage treatment plants. The use of these waters is triply beneficial; no potentially scarce freshwater needs to be used, the required nutrients are readily obtained from the wastewater, and finally, algal growth will carry out additional wastewater treatment $[3,5,39]$. Thus any truly large scale algal biofuels production facility should and probably would be built where suitable wastewaters are readily available. In fact, water use is a real issue as well in most cases since it has been estimated that each liter of algal biodiesel requires the use of 3000 liters of water $[3,5,40]$. Obviously recycling the water from algal cultivation is a necessity.

Finally, no matter how dense the algal growth is, they will need to be removed from a medium that is at least $99 \%$ water. Given their small size, this can present a formidable challenge. Although strategies exploiting biofilm formation on harvesting apparatuses are being investigated [40], most production methods require dewatering of microalgae grown in suspension [41]. Common laboratory practice, centrifugation, is of course probably out of the question considering the significant energy input required by this process, contributing to a very poor EROI. Therefore, low cost alternatives, natural settling, or flocculation assisted settling, must be used in at least the initial step with perhaps centrifugation for final dewatering of the 
now concentrated algal slurry. It might also be possible to develop a suitable membrane process for this final processing step [42-43]. A number of options are currently being explored for effective flocculation, including the use of electrical input or filamentous fungi [44-48]. Use of some variation of dissolved air flotation is promising since this technique has already proven effective in water treatment processes at removing microalgae and is relatively indifferent to species composition. The challenge is to develop a variation requiring minimal energy input $[49$, 50]. Addition of flocculating agents and detergents can increase the efficiency of this process [51].

Detailed wells to wheel EROI and LCA analyses are absolutely necessary before a particular biofuels production process can be adopted in a rational manner [37]. Part of the problem with first generation biofuels is that they were often adopted through political expediency without thorough analyses of the real energy inputs and the extended environmental impacts. In order to keep costs, both economic and energetic low, some form of dissolved are flotation or settling [41] could be good options. Settling can either take the form of selection for species with a natural tendency to settle in unmixed solutions, and/or can be further aided through the use of some sort of flocculation process.

Thus, although there is a great deal of promise in the use of microalgae for biofuels production, there are a number of significant challenges that must be overcome before this can become a practical reality. A great deal of $R \& D$ in this area is ongoing, and the next few years may well see some advances in these areas. In what follows, the various options for fuel production from harvested biomass are examined.

\subsection{Thermochemical transformation}


One possibility is to convert the entire harvested algal biomass to some type of fuel using a thermochemical process [52-61]. This is also a useful option for treating algal residues after some extraction process, for example after lipids have been extracted for biodiesel production, thus increasing total energy recovery [62]. These processes are promising since the whole algal biomass, not just the lipids or carbohydrates, can be converted into a fuel, thus special cultivation conditions, such as nitrogen deprivation to increase lipid content, are not required.

Table 4. Characteristics of different thermochemical transformations

\begin{tabular}{|c|c|c|}
\hline Thermal process & Conditions & Products \\
\hline Gasification & $900^{\circ} \mathrm{C}$, partially aerobic & Syngas $\left(\mathrm{H}_{2}, \mathrm{CO}\right)$ \\
\hline \multicolumn{3}{|l|}{ Pyrolysis } \\
\hline slow & $400{ }^{\circ} \mathrm{C}, 30 \mathrm{~min}$ ret time & $\begin{array}{l}35 \% \text { char, } 30 \% \text { liquid, } \\
35 \% \text { gas }\end{array}$ \\
\hline fast & $500^{\circ} \mathrm{C}, 10-20$ s ret time & $\begin{array}{l}20 \% \text { char, } 50 \% \text { liquid, } \\
30 \% \text { gas }\end{array}$ \\
\hline flash & $500{ }^{\circ} \mathrm{C}, 1$ s ret time & $\begin{array}{l}2 \% \text { char, } 75 \% \text { liquid, } 13 \% \\
\text { gas }\end{array}$ \\
\hline $\begin{array}{l}\text { Hydrothermal } \\
\text { carbonization }\end{array}$ & $200{ }^{\circ} \mathrm{C}$ & Lipid soaked biochar \\
\hline liquefaction & $350{ }^{\circ} \mathrm{C}$ & Biocrude \\
\hline gasification & $600^{\circ} \mathrm{C}$ & Gases $\left(\mathrm{H}_{2}, \mathrm{CH}_{4}\right)$ \\
\hline
\end{tabular}

Several options are available with the possibility of making different fuel molecules or precursors. Applying high temperatures to dry biomass in the partial or complete absence of oxygen, processes called gasification and pyrolysis respectively, transforms the biomass into a mixture of solids, liquids and gases. In a gasification reaction, high temperatures and limited amounts of oxygen are used, in conjunction with a catalyst, to decompose the various biomolecules to hydrogen and carbon monoxide, a mixture referred to as syngas. This gas mixture can either be directly combusted, or used to synthesize other, higher grade, fuels. Pyrolysis produces a mixture of biochar, bio-oil and gases (methane, hydrogen, carbon monoxide and carbon dioxide) whose relative abundance is affected by the temperature used, and hence 
requires at a minimum additional separation steps and upgrading reactions. While pyrolysis is characterized by a relatively low capital cost and relatively high biofuel yield, it suffers from the requirement for dry biomass and in general, the biofuel obtained is of rather poor fuel quality. In fact, both these processes have been little studied with respect to microalgal biomass, principally due to the requirement that the biomass be dry, incurring appreciable costs in the case of microalgae.

Alternatively, wet biomass can be used in processes that are called hydrothermal liquefaction (HTL) and catalytic hydrothermal gasification $(\mathrm{CHG})$ that take place at moderate temperatures under pressures where water is close to its supercritical state. Thus lower temperatures, but higher pressures are used than is the case for pyrolysis, incurring higher capital costs.

Hydrothermal liquefaction has the advantages that wet algal biomass can be processed and mass transfer is enhanced with supercritical water as reaction medium. In HTL and CHG, catalysts are used to accelerate the reaction and to control product distribution. On the other hand, this raises the challenges of catalyst recovery and catalyst inactivation over time. Temperature, total solids, and retention time are factors that affect bio-oil yields and quality, with one study showing an inverse relationship of temperature on these two process parameters [59].

The liquid fraction from both HTL and pyrolysis, often called bio-oil or biocrude, is in fact a complex mixture of different organic compounds, and, depending upon the exact process as well as feedstock, may require additional fractionation and upgrading to produce a drop-in fuel. One of the major challenges in producing fuels from algae in this manner is the high nitrogen content of microalgae. If left in the fuel, this $\mathrm{N}$ would lead to unacceptable levels of NOx when combusted so it must be removed during the upgrading process. In addition, in many cases the relatively high oxygen and sulfur contents of bio-crude would also be problematic if used 
directly in combustion. Fractionation of complex biocrude yields a mixture of gasoline, diesel, and heavy oil, which in one case were $25 \%, 50 \%$, and $25 \%$ respectively [57].

Catalytic hydrothermal gasification $(\mathrm{CHG})$ using supercritical water produces primarily a gas phase consisting of variable amounts of hydrogen, carbon dioxide, carbon monoxide, and methane [56]. However, this process, as presently practiced, presents a number of challenges, including the production of tars, catalyst poisoning by the sulfur that is present, and the requirement for relatively high temperatures $\left(350-500{ }^{\circ} \mathrm{C}\right)$ and pressures $(18-36 \mathrm{MPa})$. A combined continuous system, where HTL is used to convert the main incoming biomass and CHG is used to treat the process water, recovering additional energy, has been estimated to give a total conversion cost of $\$ 1.18 \mathrm{GGE}$ (gallon of gasoline equivalent) [63, 64].

\subsection{Anaerobic digestion}

A variety of biological means are available for transforming microalgal biomass or its

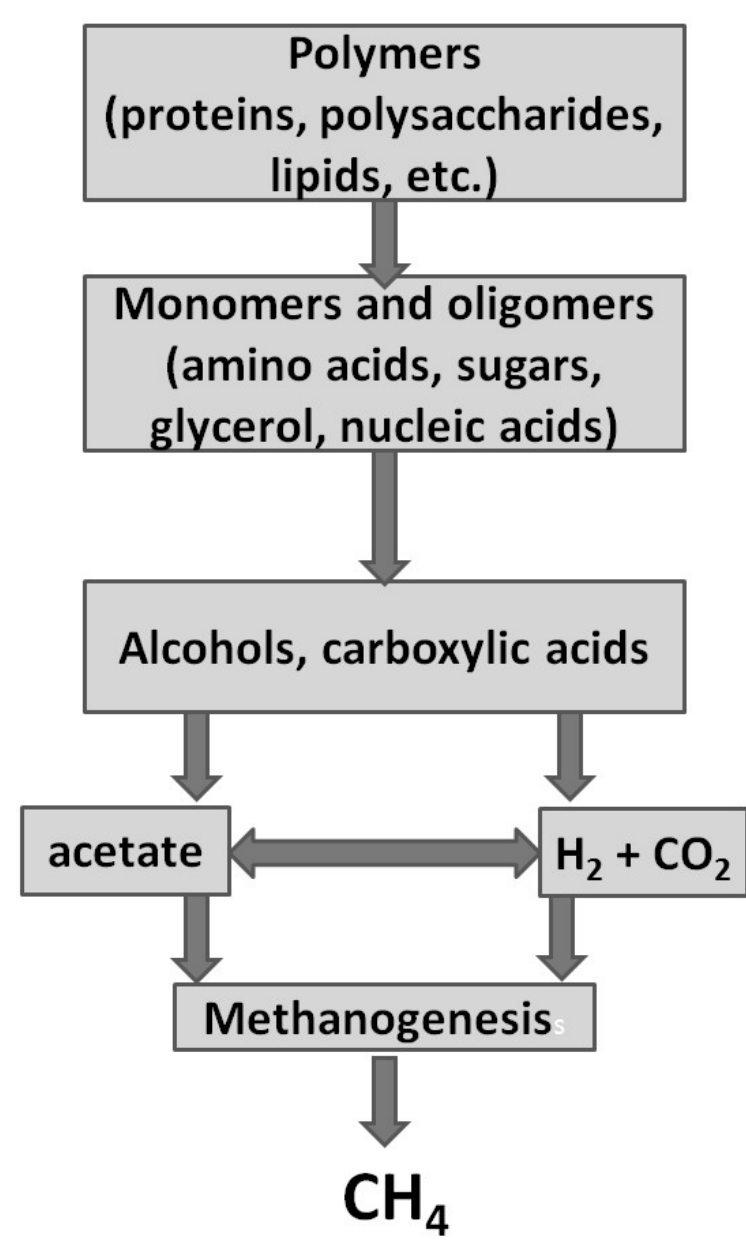

constituents to fuel compounds. Perhaps the least technically challenging is the use of anaerobic digestion which uses a host of different microbes with a wide variety of metabolic activities to convert complex organic substrates into methane and carbon dioxide (Figure 3).

\section{Conversion of various substrates to methane} proceeds through a series of steps carried out by different organisms with differing metabolic capacities. Initial depolymerization reactions free 
monomeric substrates and then coupled metabolisms are active in which the products of one type of organism serve as the substrates for the next, eventually leading to the production of methane and carbon dioxide. Since these reactions are carried out by a community of organisms, the combined degradative capacity is large and a wide variety of substrates can therefore be converted to methane. This offers the potential for conversion of the different classes of compounds in an algal cell into methane.

Anaerobic digestion is ubiquitous in nature, and is responsible for a large amount of recycling of fixed carbon each year (350-700 $\mathrm{Tg} / \mathrm{year}$ ) as well as the majority of natural gas deposits of fossil methane. Thus, this process offers the possibility to convert algal biomass, or algal biomass residues into methane [65, 66], a fuel $(55 \mathrm{MJ} / \mathrm{kg})$ already in large use in stationary applications but also adapted for transportation use, often in buses, as LNG (liquefied natural gas). Thus this process could be used directly with harvested biomass to convert this into useable energy, but is perhaps even more useful for converting algal residues that are left over after molecules that can be converted into even more useful fuels (biodiesel, bioethanol) have been extracted $[66,67]$. Not only does this increase the overall economics of the process, it effectively extracts much of the nutrients from the harvested algal biomass (nitrogen, phosphate, trace elements) allowing their return into the cultivation system. Pretreatments (thermal, ultrasonic, and alkali) to augment solubilization of the algal biomass have been investigated in an effort to increase efficiencies for methane production. However, at least some reports suggest that only very modest gains in net energy can be realized in this way, suggesting that the direct use of algal biomass is sufficient for significant methane production, probably due to the inherently strong solubilization activities of the microbial community that is present [68]. One study which examined under the same conditions a number of different strains as well as mixed 
cultures found a wide variation in actual methane yields; from 0.161 to $0.435 \mathrm{~L} \mathrm{CH}^{4} \mathrm{~g}^{-1} \mathrm{VS}$ representing a wide range in the conversion of the calorific value of the biomass (from 26 to $79 \%$ ) [69]. Of course some of this is due to differing composition, i.e. differences in lipid, carbohydrate and protein content, between different strains, but in general algal biomass has a suboptimal composition for methane digestion since with its relatively high nitrogen content it falls outside of the optimal $\mathrm{C} / \mathrm{N}$ for methane digestion, which is in the range $20-30$. One solution is to carryout co-digestion, preferably with substrates that will add additional carbon, such as paper $[70,71]$. If algal ponding operations are carried out in conjunction with wastewater treatment, an ideal situation in at least some respects as already discussed, then it makes sense to carry out a co-digestion of algal biomass with the activated sludge from the secondary wastewater treatment process [71]. Of course, the downside, and the reason that methane is really an orphan biofuel, is that it is a gas and not very readily adapted to the present day transportation infrastructure which by and large demands liquid fuels.

\subsection{Biofuels derived from storage compounds}

Many different biofuels can be derived in principle from the various storage compounds that diverse algae are capable of making. Having evolved in environments with fluctuating nutrient supplies, many microalgae are endowed with the capacity to continue to fix carbon dioxide and store the excess fixed carbon when growth is arrested for some reason, for example nitrogen limitation.

\subsubsection{Starch as reserve material}

Many algae store fixed carbon as some form of carbohydrate, most commonly starch, but some make glycogen. These are easily mobilized as glucose when the need arises. Likewise, these compounds can be extracted from the harvested algal biomass, cultivated under conditions that 
have maximized starch formation, and converted to sugars to feed some form of fermentation. In essence then, the starch-derived sugars can replace corn or sugar cane derived sugars in microbial fermentation processes leading to bioethanol or biobutanol production.

Among the many potential advantages are that, as unicellular organisms, microalgae contain the desired feedstock in every cell, and hence there are no auxiliary materials, such as roots or stalks, that become residues that have taken some of the converted solar energy to make but which are not used in fuel production. This in itself inherently increases efficiency. Microalgae, depending upon the species and cultivation conditions, can be up to about $50 \%$ starch by weight [72], quite often accumulating in the plastid (chloroplast) but sometimes in the cytosol [73]. Interestingly, one study using Chlorella sorokiniana, found that not only did growth under higher $\mathrm{pCO}_{2}\left(\mathrm{CO}_{2}\right.$ partial pressure $)$ increase biomass, as commonly observed, but it also changed the location of the accumulated starch, from the plastid to the stroma, as well as its structure, making it more easily deconstructed [74]. Various factors, including nutrient limitation, can increase starch accumulation, and the accumulated starch can in principle be either be directly fermented by endogenous metabolism to ethanol [75], or be extracted and converted to sugars [76] followed by a more conventional yeast fermentation.

\subsubsection{Lipid (TAGs) as reserve material}

Microalgae are widely known for their propensity to accumulate large amounts (up to $80 \%$ by dry weight) of neutral lipids that can be converted to biodiesel [7-10, 26, 27]. While special conditions are probably required to get an extremely high lipid content, strains can easily be isolated that achieve lipid levels of 30 to $40 \%$ on a dry weight basis without extensive manipulation $[77,78]$. This process is under extensive $R \& D$ with over 100 start-up companies formed and over one billion invested over the past decade. Although some of this frenzy has 
been caused by overly optimistic claims, there are a number of attractive features to such a process, not the least of which is that, depending upon the species, a biodiesel with drop-in fuel characteristics can be made.

Of course, there is still much debate about the best way to develop a practical process out of this system [79]. In fact, there are unresolved issues surrounding each of the various stages of liquid (biodiesel) production using microalgae. It is not even evident how they should be cultivated at large scale given the number of significant challenges. This issue was already raised in section 2.2 but further discuss here is warranted since this remains a very active area of discussion for this biofuels pathway. Two basic methods have been proposed, enclosed photobioreactors and open raceway ponds (Table 3). In terms of bioprocess control and maintenance of the desired species, enclosed photobioreactors obviously have the upper hand. Although it would hardly be practical at scale, specialized bioreactors can be used to increase the effective use of solar irradiance. For example, the use of outdoor flat solar panels with sun tracking capabilities can improve biomass accumulation through photoinhibition reduction and improved temperature control [80]. On the other hand, it would seem that the large differences in anticipated CAPEX and OPEX would mean that only open raceway ponds will make practical economic sense for low value products such as fuels. Additional factors to consider include the fact that at scale enormous quantities of water and nutrients will be required. Although in some locales and some situations the use of amended sea water might work, in general advantage needs to be taken of the enormous supplies of wastewater, primarily from sewage treatment, that are available worldwide $[7,8,81,82]$. The use of wastewater should help reduce the overall costs of microalgae cultivation, reducing potentially expensive nutrient addition as well as obtaining credits for wastewater treatment. Many strains of algae grow quite happily in such a 
medium with little or no supplementation and, additionally, some can be quite effective at removing remaining nitrate and phosphate form these waters [77, 78, 83, 84].

One of the major challenges in the algae to biodiesel process is to find that produces high yields of biodiesel without requiring large amounts of energy or the use of toxic solvents. Thus, different novel extraction and conversion procedures are under active investigation [85-86]. One possibility is to use switchable solvents which can be cycled between a polar and a nonpolar character simply by using $\mathrm{CO}_{2}$, eliminating the need for solvent recovery through distillation [88]. Equally promising is the recent demonstration of a wet lipid extraction procedure allowing relatively high (80\%) recovery of lipids from wet algal biomass (84\% moisture content) [89-93].

Although practical systems capable of delivering biodiesel derived from algae at prices competitive at the pump with fossil diesel are not yet there, production is ramping up in attempts to meet various government mandates, including the US Navy's Green Fleet initiative [94]. Given the large amount of activity and interest in this area of biofuels production there will soon be a number of pilot plants of significant size in operation and data on real world operations will start to accumulate. Practicality will depend upon how well engineering and science can overcome the challenges as this process scales to significant size.

\subsection{Hydrogen production by algae}

Hydrogen has many desirable characteristics as a fuel, including the highest gravimetric energy density (142 MJ/kg), the ability to be converted efficiently into electricity through the use of fuel cells (94\% compared to a maximum of about $60 \%$ for internal combustion engines), and having very clean combustion products $\left(\mathrm{H}_{2} \mathrm{O}\right)$. For many years, researchers have been pursuing the dream of making hydrogen by using water splitting catalyzed by biological photosynthesis. As has been known for many years, some microalgae contain the enzyme hydrogenase and are 
capable of using it to reduce protons to hydrogen when re-illuminated after a period of dark adaptation during which the culture has become anaerobic. The problem is that such a reaction is normally short-lived since the newly generated oxygen quickly inactivates the hydrogenase enzyme which is extremely sensitive to oxygen $[95,96]$.

Therefore, to realize the dream of generating hydrogen from the almost limitless substrate, water, by capturing solar energy though photosynthesis, this serious challenge must somehow be overcome. A number of strategies are being applied in attempts to circumvent this oxygen problem. On the one hand, nutrient deprivation, in particular sulfur, has been shown to lead to prolonged periods of hydrogen evolution. However, this occurs because total photosynthesis is decreased to the extent that respiration with the supplied acetate can soak up all the oxygen that is evolved through photosynthesis. This is not practical for two reasons [96]. Photosynthetic efficiencies are already low (Figure 2) so decreasing this further is a step in the wrong direction. Furthermore, use of a fixed carbon substrate also represents a loss in photosynthetic efficiency since this also is a product at some point of photosynthesis.

Another strategy is to develop oxygen tolerant hydrogenases $[95,96]$, but in reality this is a daunting task given the very small sizes involved of both the poisoning oxygen and the product, hydrogen. Oxygen is toxic due to its attack on the highly reactive active site, a complex arrangement of iron, sulfur, and ligands like CO and CN. It is unclear how to prevent access of $\mathrm{O}_{2}$ to this site, buried within the protein, while at the same time allowing the $\mathrm{H}_{2}$ that is generated to escape. Likewise, it is unclear how one would change the active site to make it less reactive to oxygen yet still have high activity towards proton reduction.

\subsection{Metabolic engineering}


Finally, metabolic engineering could be applied to solar biofuels production in a number of ways. Different aspects could conceivably be changed to make this a more efficient process [96101]. These improvements could include extending the range of light capture and making photosynthesis more efficient at high light intensities by reducing the size of the photosynthetic antennae. In another approach, metabolic alterations could be carried out to channel more of the captured energy towards production of the desired product by, for example, eliminating competing pathways, or increasing the amounts and activity of the enzymes involved in product formation [102-104]. As more information on the regulation of lipid production is gleaned from the analysis of transcriptomes and lipidomes [105, 106], additional targets for metabolic engineering may be revealed. Meanwhile, the molecular toolkit for the genetic engineering of microalgae is growing ever larger and more sophisticated, with applications in production strains such as Nannocholorpsis oculata and Phaeodactylum tricornutum as well as model organisms such as Chlamydomonas reinhardtii [107-109]. Finally, the quality or type of fuel could be changed through the application of these strategies and techniques. Methods pioneered to enhance production of commercially important nutraceuticals like omega-3 long chain polyunsaturated fatty acids could similarly be developed to optimize biofuel production [110, 111]. For example, fatty acid chain length or saturation could be tailored so that a fuel, biodiesel or biojet, with the desired characteristics is made [112]. It is even possible to envisage in the future algae endowed with new pathways capable of producing chemicals and fuels, such as ethylene, not possible with native cells.

\subsection{Conclusion}

Algae seem uniquely poised to enable the production of solar biofuels. These, in theory, can be made at high productivities without competing with food production. Additional benefits could 
be wastewater treatment and the development of biofertilizers. Nevertheless, a number of significant technical challenges prevent a large scale practical implementation of algal technologies for fuel production at present. Research and development work currently underway in a large number of academic and private enterprise laboratories worldwide promises to provide solutions to many of these problems in the short to medium term.

\section{Acknowledgments}

The views expressed in this article are those of the authors and do not reflect the official policy or position of the United States Air Force, the Department of Defense, or the US Government. PCH holds a National Research Council Senior Research Associateship Award at the Life Sciences Research Center, Department of Biology, United States Air Force Academy.

\section{References}

[1] EIA US Energy Information Agency http://www.eia.gov/cfapps/ipdbproject/IEDIndex3.cfm?tid=79\&pid=79\&aid=1 accessed 25-112015

[2] Karp A, Richter GM, Meeting the challenge of food and energy security, Journal of Experimental Botany 2011;62:3263-3271

[3] Editorial Kill king corn. Nature 2007;449:637

[4] Fargione J, Hill J, Tilman D, Polasky S, Hawthorne P. Land clearing and the biofuel carbon debt. Science 2008;319:1235-1238 .

[5] Hallenbeck PC. Biofuels, the Larger Context P.C. Hallenbeck (ed.), Microbial Technologies in Advanced Biofuels Production (2012), pp.3-12. DOI 10.1007/978-1-4614-1208-3_1 
[6] ISSD International Institute for Sustainalbe Development

http://www.iisd.org/publications/biofuels\%E2\%80\%94-what-cost-review-costs-and-benefits-eubiofuel-policies accessed 25-11-2015

[7] Abdelaziz AEM, Leite GB, Hallenbeck PC. Addressing the challenges for sustainable production of algal biofuels: I. Algal strains and nutrient supply. Environ Technol 2013;34:1783-1805.

[8] Abdelaziz AEM, Leite GB, Hallenbeck PC. Addressing the challenges for sustainable production of algal biofuels: II. Harvesting and conversion to biofuels. Environ Technol 2013;34:1807-1836.

[9] Leite GB, Abdelaziz AEM, Hallenbeck PC. Algal biofuels: Challenges and opportunities. Biores Technol 2013;145:134-141.

[10] Leite GB, Hallenbeck PC. Algae Oil. In Microbial Technologies in Advanced Biofuels Production, Hallenbeck, P.C., ed. Springer, 2012. p.231-259.

[11] Popp J, Z. Lakner, ZM. Harangi-Rákos, M. Fári, The effect of bioenergy expansion: Food, energy, and environment, Renewable and Sustainable Energy Reviews 2014;32:559-578. [12]EIA (Energy Information Agency) http://www.eia.gov/totalenergy/data/monthly/pdf/sec2_11.pdf accessed Nov. 28, 2015 [13] Worldbank http://data.worldbank.org/indicator/AG.LND.ARBL.HA.PC accessed Nov. 28, 2015

[14] Van Den Hende S, Vervaeren H, Boon N. Flue gas compounds and microalgae: (Bio-) chemical interactions leading to biotechnological opportunities Biotech Adv 2012; 30(6):14051424.

[15] Bhave R, Kuritz T, Powell L, Adcock D. Membrane-based energy efficient dewatering of microalgae in biofuels production and recovery of value added co-products. Environ. Sci. Technol 2012;46 (10):5599-5606.

[16] Benemann J. Microalgae for Biofuels and Animal Feeds. Energies 2013;(6):5869-5886. 
[17] Bhateria R, Dhaka R. Algae as Biofuel. Biofuels 2015. Published online at DOI:10.1080/17597269.2014.1003701

[18] Acién FG, Fernández JM, Magán JJ, Molina E. Production cost of a real microalgae production plant and strategies to reduce it. Biotech Adv 2012;30(6):1344-1353.

[19] Chow MC, Jackson WR, Chaffee AL,Marshall M. Thermal Treatment of Algae for Production of Biofuel. Energy and Fuels 2013;27:1926-1950.

[20] Gerken HG, Donohoe B, Knoshaug EP. Enzymatic cell wall degradation of Chlorella vulgaris and other microalgae for biofuels production. Planta 2013;237:239-253.

[21] Larkum AWD, Ross IL, Kruse O, Hankamer B. Selection, breeding and engineering of microalgae for bioenergy and biofuel production. Trends in Biotech 2012;30(4):198-205. [22] Davies FK, Jinkerson RE, Posewitz MC. Toward a photosynthetic microbial platform for terpenoid engineering, Photosynthesis Research 2015;123:265-284.

[23] Radakovits R, Jinkerson RE, Darzins A, Posewitz MC. Genetic Engineering of Algae for Enhanced Biofuel Production, Eukaryotic Cell 2010;9:486-501.

[24] Work VH, Bentley FK, Scholz MJ, D'Adamo S, Gu H, Vogler BW, Franks DT, Stanish LF, Jinkerson RE, Posewitz MC. Biocommodities From Photosynthetic Microorganisms, Environmental Progress \& Sustainable Energy 2013;32:989-1001.

[25] Rawat I, Ranjith K, Mutanda T, Bux F. Biodiesel from microalgae: A critical evaluation from laboratory to large scale production. Applied Energy 2013;103:444-467.

[26] Bahadar A, Khan MB. Progress in energy from microalgae: A review. Renew Sustain Energy Rev 2013;27, 128-148.

[27] Suali E, Sarbatly R. Conversion of microalgae to biofuel. Renew Sustain Energy Rev 2012;16:4316-4342.

[28] Mooij PR, Stouten GR, van Loosdrecht MCM, Kleerebezem R. Ecology-based selective environments as solution to contamination in microalgal cultivation. Current Opinion in Biotechnology 2015;33:46-51

[29] Mata TM, Martins AA, Caetano NS. Microalgae for biodiesel production and other applications : a review. Ren Sust Energy Rev. 2010;14:217-232

[30] Benemann JR, Oswald WJ. Systems and economic analysis of microalgae ponds for conversion of CO2 to biomass, Final Report to the Department of Energy. Pittsburgh Energy Technology Center, 1996. 
[31] Lundquist TJ, Woertz IC, Quinn NWT, and J.R. Benemann. A Realistic Technology and Engineering Assessment of Algae Biofuel Production. Energy Biosciences Institute, October 1, 2010, pages 1-178.

[32] National Research Council (U.S.) 2012. Sustainable development of algal biofuels in the United States. Washington, D.C. National Academies Press

[33] Chen P, Min M, Chen Y, Wang L, Li Y, Chen Q, Wang C, Wan Y, Wang X, Cheng Y, Deng S, Henessy K, Lin X, Liu Y,Wang Y, Martinez B, Ruan R. Review of the biological and engineering aspects of algae to fuels approach. Int J Agric \& Biol Eng, 2009;2(4):1-30 [34] Ugwu CU, Aoyagi H, Uchiyama H. Photobioreactors for mass cultivation of algae. Bioresource Technology 2008;99:4021-4028

[35] Richardson JW, Johnson MD, Outlaw JL. Economic comparison of open pond raceways to photo bio-reactors for profitable production of algae for transportation fuels in the Southwest, Algal Research 2012;1:93-100.

[36] Slade R, Bauen A. Micro-algae cultivation for biofuels: Cost, energy balance, environmental impacts and future prospects, Biomass and Bioenergy 2013;53:29-38.

[37] Jonker JGG, Faaij APC. Techno-economic assessment of micro-algae as feedstock for renewable bio-energy production. Appl Energy 2013;102:461-475.

[38] Jorquera O, Kiperstok A, Sales EA, Embiruçu M, Ghirardi ML. Comparative energy lifecycle analyses of microalgal biomass production in open ponds and photobioreactors.

Bioresource Technology 2010;101(4):1406-1413.

[39] Mehrabadi A, Rupert Craggs R, Farid MM. Wastewater treatment high rate algal ponds (WWT HRAP) for low-cost biofuel production. Bioresource Technology 2015;184:202-214 [40] Farooq W, Suh WI, Park MS, Yang J-W. Water use and its recycling in microalgae cultivation for biofuel application. Bioresource Technology 2015;184:73-81

[41] Milledge J, Heaven S, A review of the harvesting of micro-algae for biofuel production, Rev Environ Sci Biotechnol 2013;12:165-178.

[42] Gross M, Jarboe D, Wen Z. Biofilm-based algal cultivation systems. Appl Microbiol Biotechnol 2015;99(14):5781-5789.

[43] Mo W, Soh L, Werber JR, Elimelech M, Zimmerman JB. Application of membrane dewatering for algal biofuel, Algal Research-Biomass Biofuels and Bioproducts. 2015;11:1-12. 
[44] ‘t Lam GP, Vermuë MH, Olivieri G, van den Broek LAM, Barbosa MJ, Eppink MHM, Wijffels RH, Kleinegris DMM. Cationic polymers for successful flocculation of marine microalgae. Biores Technol 2014;169:804-807.

[45] Liu J, Tao Y, Wu J, Zhu Y, Gao B, Tang Y, Li A, Zhang C, Zhang Y. Effective flocculation of target microalgae with self-flocculating microalgae induced by $\mathrm{pH}$ decrease. Biores Technol 2014;167:367-375.

[46] Valero E, Alvarez X, Cancela A, Sanchez A. Harvesting green algae from eutrophic reservoir by electroflocculation and post-use for biodiesel production. Bioresour Technol $2015 ; 187: 255-262$.

[47] Muradov N, Taha M, Miranda AF, Wrede D, Kadali K, Gujar A Stevenson T, Ball AS, Mouradov A. Fungal-assisted algal flocculation: application in wastewater treatment and biofuel production. Biotechnol Biofuels 2015;8:24.

[48] Wrede D, Taha M, Miranda AF, Kadali K, Stevenson T, Ball AS, Mouradov A. CoCultivation of Fungal and Microalgal Cells as an Efficient System for Harvesting Microalgal Cells, Lipid Production and Wastewater Treatment. PLoS One. 2014;9(11):e113497. [49] Salim, S., Gilissen, L., Rinzema, A., Vermuë, M.H., Wijffels, R.H. Modeling microalgal flocculation and sedimentation Bioresour. Technol., 144 (2013), pp. 602-607 [50] Zhang, Z., Hewson, J.C., Amendola, P., Monica Reynoso, M., Sommerfeld, M., Chen, Y., Hu, Q. Critical Evaluation and Modeling of Algal Harvesting Using Dissolved Air Flotation. Biotechnology and Bioengineering, 111 (2014), 2477-2485

[51] Gerardo, M.L., Van Den Hende, S., Vervaeren, H., Coward, T., Skill, S.C. Harvesting of microalgae within a biorefinery approach: A review of the developments and case studies from pilot-plants. Algal Research 11 (2015) 248-262 
[52] Yeh TM, Dickinson JG, Franck A, Linic S, Thompson LT Jr, Savage PE. Hydrothermal catalytic production of fuels and chemicals from aquatic biomass. J Chem Technol Biotech 2013;88:13-24.

[53] Roberts GW, Fortier M-OP, Sturm BSM, Stagg-Williams, SM. Promising Pathway for Algal Biofuels through Wastewater Cultivation and Hydrothermal Conversion. Energy Fuels 2013:27:857-867.

[54] Marcilla A, Catalá L, García-Quesada JC, Valdés FJ, Hernández MR. A review of thermochemical conversion of microalgae. Renew Sustain Energy Rev 2013;27:11-19 [55] Patel B, Guo M, Izadpanah A, Shah N, K. Hellgardt K. A review on hydrothermal pretreatment technologies and environmental profiles of algal biomass processing, Bioresource technology 2016;199:288-299.

[56] Chen W-H, Lin B-J, Huang M-Y, Chang J-S. Thermochemical conversion of microalgal biomass into biofuels: A review, Bioresource Technology 2015;184:314-327.

[57] Biller P, Sharma BK, Kunwar B, Ross AB. Hydroprocessing of bio-crude from continuous hydrothermal liquefaction of microalgae, Fuel 2015;159:197-205.

[58] Yang W, Li X, Li Z, Tong C, Feng L. Understanding low-lipid algae hydrothermal liquefaction characteristics and pathways through hydrothermal liquefaction of algal major components: Crude polysaccharides, crude proteins and their binary mixtures, Bioresource Technology 2015;196:99-108.

[59] Yoo G, Park MS, Yang J-W, Choi M. Lipid content in microalgae determines the quality of biocrude and Energy Return On Investment of hydrothermal liquefaction, Applied Energy 2015;156:354-361.

[60] Raheem A, Azlina WAKGW, Yap YHT, Danquah MK, Harun R. Thermochemical conversion of microalgal biomass for biofuel production Renewable \& Sustainable Energy Reviews 2015;49:990-999.

[61] Ponnusamy S, Reddy HK, Muppaneni T, Downes CM, Deng S. Life cycle assessment of biodiesel production from algal bio-crude oils extracted under subcritical water conditions, Bioresource Technology 2014;170:454-461.

[62] Selvaratnam T, Pegallapati AK, Reddy H, Kanapathipillai N, Nirmalakhandan N, Deng S, Lammers PJ. Algal biofuels from urban wastewaters: Maximizing biomass yield using nutrients recycled from hydrothermal processing of biomass, Bioresource Technology 2015;182:232-238. 
[63] Jones, S., Davis, R., Zhu, Y., Kinchin, C., Anderson, D., Hallen, R., Elliott, D., Schmidt, A., Albrecht, K., Hart, T., Butcher, M., Drennan, C., Snowden-Swan, L. 2014. Process Design and Economics for the Conversion of Algal Biomass to Hydrocarbons: Whole Algae Hydrothermal Liquefaction and Upgrading.

http://www.pnnl.gov/main/publications/external/technical_reports/PNNL-23227.pdf

[64] Elliott, D.C., Biller, P., Ross, A.B., Schmidt, A.J., Jones, S.B., 2015. Hydrothermal liquefaction of biomass: Developments from batch to continuous process. Bioresource Technology 178, 147-156.

[65] Sialve B, Bernet N, Bernard O. Anaerobic digestion of microalgae as a necessary step to make microalgal biodiesel sustainable. Biotechnol Adv 2009;27:409-416.

[66] Ward AJ, Lewis DM, Green FB. Anaerobic digestion of algae biomass: A review. Algal Res. 2014;5:204-214.

[67] Quinn JC, Hanif A, Sharvelle S, Bradley TH. Microalgae to biofuels: Life cycle impacts of methane production of anaerobically digested lipid extracted algae. Biores Technol 2014;171:3743.

[68] Cho S, Park S, Seon J, Yu J, Lee T. Evaluation of thermal, ultrasonic and alkali pretreatments on mixed-microalgal biomass to enhance anaerobic methane production. Biores Technol 2013;143:330-336.

[69] Roberts KP, S. Heaven S, C.J. Banks CJ. Comparative testing of energy yields from microalgal biomass cultures processed via anaerobic digestion. Renewable Energy 2016;87:744-753. [70] Amritha A, Thanikal JV, Narayanan CM, Kumar RS An overview of bio augmentation of methane by anaerobic co-digestion of municipal sludge along with microalgae and waste paper Renewable and Sustainable Energy Reviews 2015;50:270-276

[71] Yen HW, Brune DE. Anaerobic co-digestion of algal sludge and waste paper to produce methane. Bioresour Technol 2007;98:130-4.

[72] Brányiková I, Maršálková B, Doucha J, Brányik T, Bišová K, Zachleder V, Vítová M. Microalgae — novel highly efficient starch producers. Biotechnology and Bioengineering, 2011;108:766-776.

[73] Busi MV, Barchiesi J, Martın M, Gomez-Casati F. Starch metabolism in green algae.

Starch/Starke 2013;66:28-40 
[74] Tanadul OU, VanderGheynst JS, Beckles DM, Powell AL, Labavitch JM. The impact of elevated $\mathrm{CO} 2$ concentration on the quality of algal starch as a potential biofuel feedstock.Biotechnol Bioeng. 2014;111(7):1323-1331.

[75] Ueno Y, Kurano N, Miyachi S. Ethanol production by dark fermentation in the marine alga Chlorococcum litoralie. J. Ferment. Bioeng.1998;86:38-43.

[76] Harun R, Danquah M, Enzymatic hydrolysis of microalgal biomass for bioethanol production. Chem Eng J 2011;168:1079-1084.

[77] Abdelaziz AEM, Leite GB, Belhaj MA, Hallenbeck PC. Screening microalgae native to Quebec for wastewater treatment and biodiesel production. Biores Technol 2014;157:140-148. [78] Hallenbeck PC, Leite GB, Abdelaziz AEM. Exploring the Diversity of Microalgal Physiology for Applications in Wastewater Treatment and Biofuels Production Algal Res 2014. [79] Medipally SR, Yusoff FM, Banerjee S, Shariff M. Microalgae as sustainable renewable energy feedstock for biofuel production. Biomed Res Int. 2015; Epub.

[80] Hindersin S, Leupold M, Kerner M, Hanelt D. Irradiance optimization of outdoor microalgal cultures using solar tracked photobioreactors. Bioprocess Biosyst Eng 2013; Volume 36, Issue 3, 345-355.

[81] Bhatt NC, Panwar A, Bisht TS, Tamta S. Coupling of algal biofuel production with wastewater. Scientific World Journal. 2014; Epub.

[82] Drexler IL, Joustra C, Prieto A, Bair R, Yeh DH. AlgaeSim: a model for integrated algal biofuel production and wastewater treatment. Water Environ Res 2014;86(2):163-176.

[83] Racharaks R, Ge X, Li Y. Cultivation of marine microalgae using shale gas flowback and anaerobic digestion effluent as the cultivation medium. Bioresour Technol 2015;191:146-156. 
[84] Zhang SS, Liu H, Fan JF, Yu H. Cultivation of Scenedesmus dimorphus with domestic secondary effluent and energy evaluation for biodiesel production. Environ Technol 2015;36(7):929-936.

[85] de Boer, K., Moheimani, N.R., Borowitzka, M.A., Bahri, P.A., 2012. Extraction and conversion pathways for microalgae to biodiesel: a review focused on energy consumption. J. Appl. Phycol. 24, 1681-1698.

[86] Kumar, R.R., Rao, P.H., Arumugam, M. 2015. Lipid extraction methods from microalgae: A comprehensive review. Frontiers in Energy Research 2:1-9.

[87] Halim, R., Danquah, M.K., Webley, P.A., 2012. Extraction of oil from microalgae for biodiesel production: A review. Biotechnology Advances 30, 709-732.

[88] Boyd, A.R., Champagne, P., McGinn, P.J., MacDougall, K.M., Melanson, J.E., Jessop, P.G., 2012. Switchable hydrophilicity solvents for lipid extraction from microalgae for biofuel production. Bioresour. Technol. 118, 628-632 [89] Sathish, A., Sims, R.C., 2012. Biodiesel from mixed culture algae via a wet lipid extraction procedure. Bioresour. Technol. 118, 643-647. [90] Cheng J, Huang R, Li T, Zhou J, Cen K. Biodiesel from wet microalgae: Extraction with hexane after the microwave-assisted transesterification of lipids. Biores Technol 2014;170: 6975.

[91] Zhang X, Yan S, Tyagi RD, Surampalli RY, Valéro JR. Ultrasonication aided in-situ transesterification of microbial lipids to biodiesel. Biores Technol 2014;169:175-180. [92] Park J-Y, Park MS, Lee Y-C, Yang J-W. Advances in direct transesterification of algal oils from wet biomass, Bioresource Technology 2015;184:267-275. 
[93] Sathish A, Marlar T, Sims RC. Optimization of a wet microalgal lipid extraction procedure for improved lipid recovery for biofuel and bioproduct production. Bioresource Technology 2015;193:15-24.

[94] Chambers AM, Yetiv SA. THE GREAT GREEN FLEET The U.S. Navy and Fossil-Fuel Alternatives Naval War College Review, Summer 2011, Vol. 64, No. 3 61-77.

[95]Hallenbeck PC. Microbial paths to renewable hydrogen production. Biofuels 2011;2: 285302

[96] Hallenbeck PC, Abo-Hashesh M, Ghosh D. Strategies for improving biological hydrogen production. Biores Technol 2012;110:1-9.

[97] Radakovits R, Jinkerson RE, Darzins A, Posewitz MC. Genetic engineering of algae for enhanced biofuel production. Eukaryot Cell 2010; 9:486-501.

[98] Beer LL, Boyd ES, Peters JW, Posewitz MC. Engineering algae for biohydrogen and biofuel production. Curr Opin Biotechnol 2009;20:264-271.

[99] Hegde K, Chandra N, Sarma SJ, Brar SK, Veeranki VD. Genetic Engineering Strategies for Enhanced Biodiesel Production. Mol Biotechnol 2015;57(7):606-624.

[100] Scranton MA, Ostrand JT, Fields FJ, Mayfield SP. Chlamydomonas as a model for biofuels and bio-products production. Plant J 2015;82(3):523-531.

[101] Lee SY, Kim HM, Cheon S. Metabolic engineering for the production of hydrocarbon fuels. Curr Opin Biotechnol 2015;33:15-22.

[102] Dubini A, Ghirardi M. Engineering photosynthetic organisms for the production of biohydrogen. Photosynth Res 2015;123:241-253.

[103] Ghirardi ML. Implementation of photobiological $\mathrm{H} 2$ production: the $\mathrm{O} 2$ sensitivity of hydrogenases. Photsynth Res 2015; Epub. 
[104] Muto M, Tanaka M, Liang Y, Yoshino T, Matsumoto M, Tanaka T. Enhancement of glycerol metabolism in the oleaginous marine diatom Fistulifera solaris JPCC DA0580 to improve triacyclglyerol productivity. Biotechnol Biofuels 2015;8(1):4.

[105] Jia J, Han D, Gerken HG, Li Y, Sommerfeld M, Hu Q, Xu J. Molecular mechanisms for photosynthetic carbon partitioning into storage neutral lipids in Nannochloropsis oceanica under nitrogen-depletion conditions. Algal Research 2015; 7:66-77.

[106] Li J, Han D, Wang D, Ning K, Jia J, Wei L, Jing X, Huang S, Chen J, Li Y, Hu Q, Xu J. Choreography of transcriptomes and lipidomes of Nannochloropsis reveals the mechanisms of oil synthesis in microalgae. Plant Cell 2014;26(4):1645-1665.

[107] Rasala BA, Chao SS, Pier M, Barrera DJ, Mayfield SP. Enhanced genetic tools for engineering multigene traits into green algae. PLoS One 2014; 9(4):e94028.

[108] Shih CH, Chen HY, Lee HC, Tsai HJ. Purple chromoprotein gene serves as a new selection marker for transgenesis of the microalga Nannochloropsis oculata. PLoS One 2015;10(3):e0120780.

[109] Xue J, Niu YF, Huang T, Yang WD, Liu JS, Li HY. Genetic improvement of the microalga Phaeodactylum tricornutum for boosting neutral lipid accumulation. Metab Eng $2015 ; 27: 1-9$.

[110] Hamilton ML, Haslam RP, Napier JA, Sayanova O. Metabolic engineering of Phaeodactylum tricornutum for the enhanced accumulation of omega-3 long chain polyunsaturated fatty acids. Metab Eng 2014; 22:3-9.

[111] Kaye Y, Grundman O, Leu S, Zarka A, Zorin B, Didi-Cohen S, Khozin-Goldberg I, Boussiba S. Metabolic engineering toward enhanced LC-PUFA biosynthesis in Nannochloropsis 
oceanica: Overexpression of endogenous delta12 desaturase driven by stress-inducible promotor leads to enhanced deposition of polyunsaturated fatty acids in TAG. Algal Research 2015; Epub. [112] Ahmad I, Sharma AK, Daniell H, Kumar S. Altered lipid composition and enhanced lipid production in green microalga by introduction of brassica diacylglycerol and acyltransferase 2 . Plant Biotechnol J 2015;13(4)540-550. 


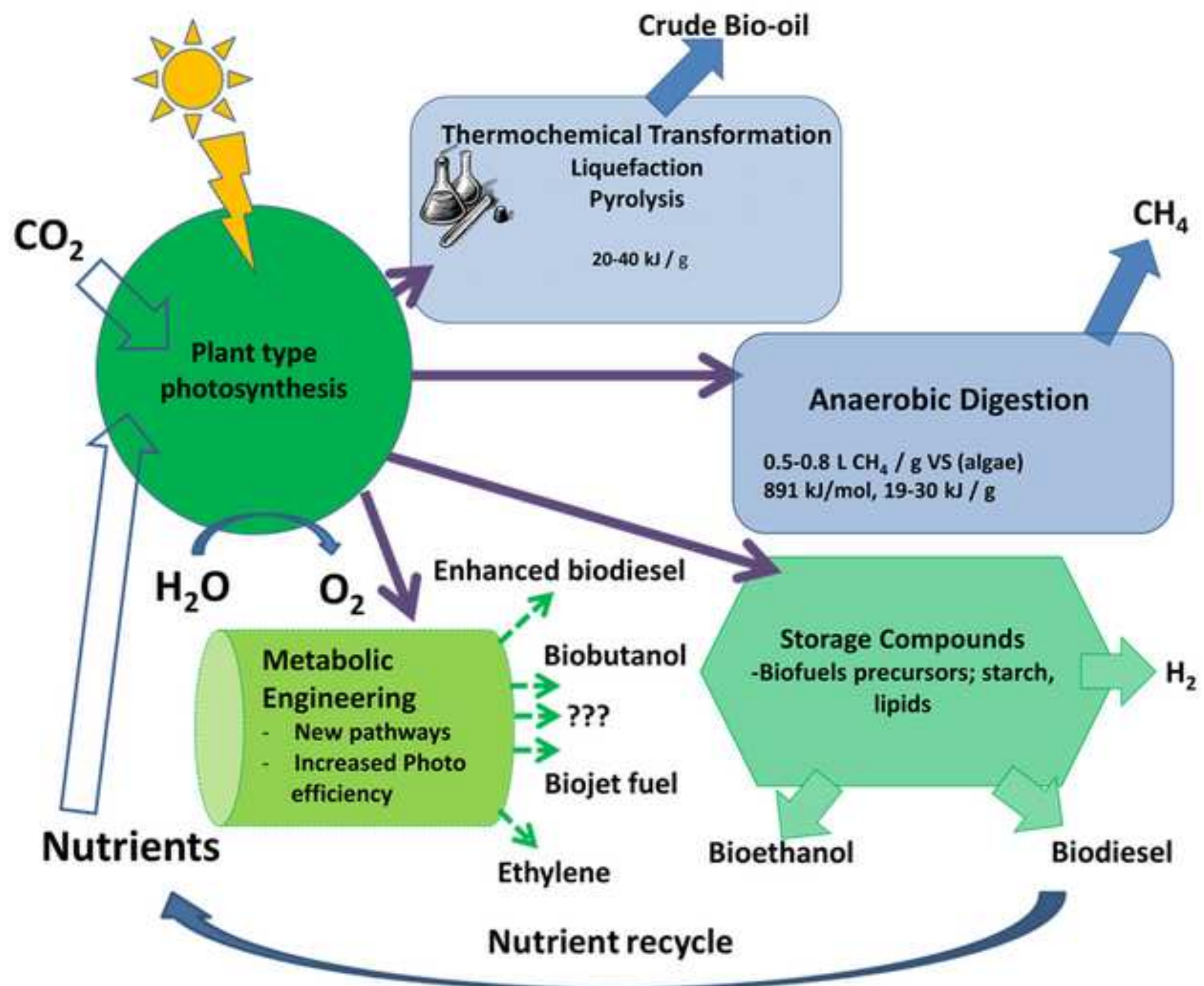

